\title{
Outcome of bone marrow derived chondrocyte injection for meniscal injuries: A preliminary study
}

\author{
Hasan N AlSayed ${ }^{1}$, Mir Sadat-Ali ${ }^{*}$, Fares Z Uddin ${ }^{2}$, Fawaz M Alani ${ }^{3}$ and Sadananda Acharya ${ }^{4}$ \\ ${ }^{1}$ Department of Orthopaedic Surgery, College of Medicine, Imam AbdulRahman Bin Faisal University, Dammam, Saudi Arabia \\ ${ }^{2}$ King Hamad University Hospital, Bahrain \\ ${ }^{3}$ King Fahd Hospital of the University, AlKhobar, Saudi Arabia \\ ${ }^{4}$ College of Public Health, Imam AbdulRahman Bin Faisal University, Dammam, Saudi Arabia
}

\begin{abstract}
Background and objective: Meniscus retention after injuries important for long-term effective functioning of the knee joint and injured meniscus usually require surgical repair. This preliminary study was conducted to determine if injection of Bone Marrow Derived Chondrocytes (BMDC) will regenerate the injured meniscus.

Patients and methods: In 15 patients, twenty CC of Bone marrow was aspirated under aseptic technique under local anesthesia and sedation and in vitro chondrocyte was expanded from the mesenchymal stem cells. After three weeks of bone marrow aspiration 5 million chondrocytes were injected in the effected knee joint. Patients were followed up in the clinics and data collected of pain and range of movements. At 3 months the knee joint was assessed by clinical examination and a magnetic resonance imaging was done and pre and post injection MRI was evaluated by the musculo-skeletal radiologist who was blinded of the MRI scans.

Results: Fourteen patients were in the study group which could be analyzed. The mean age of patients was $36.4 \pm 5.1$ years. There were complaints of any side effects of the Bone marrow aspirated neither site nor the site of injection in the knee. The average pain score pre-injection was $6.36 .3 \pm 1.25$ compared to 90 days post injection was $1.4 \pm 0.51(\mathrm{P}<0.0001)$. The range of movements Flexion improved from $90.4 \pm 10.13$ to $116 \pm 5.16(\mathrm{P}<0.001)$. Post injection $\mathrm{MRI}$ showed the healing of the all the meniscus with good thickness.
\end{abstract}

Conclusion: Our study shows that BMDC injection in the knee joint showed great potential to heal the injured meniscus. This calls for further randomized control studies.

\section{Introduction}

There are two meniscuses in the knee joint are supposed to fulfill important functions, to transfer the load from the femur to the tibia and stabilize the knee during flexion, extension and minimal rotation, load-bearing and as well as lubrication and nutrition of articular cartilage [1]. With all these functions to be performed no wonder the menisci are the most common to be injured. It was reported that over 25000 admission takes place each year due to meniscus injuries in England and Wales [2]. Injured meniscus were initially removed partially or completely causing many fold increased risk of early osteoarthritis [3-5]. This led to surgeons to preserve the meniscus with repair and many techniques are in vogue but have their own complications [6-10]. It is known that human body has limited ability to self-repair torn meniscus and recent studies generated hope that articular cartilage can be regenerated under the influence of mesenchymal stem cells (MSCs) in patients with torn meniscus [11,12]. Centeno and colleagues (2008) reported a case in which autologous mesenchymal stem cells healed a torn meniscus with significant cartilage growth, decreased pain and increased joint mobility of the treated joint. Whitehouse et al (2017) used First-inHuman Trial of the Autologous MSC/Collagen- Scaffold Implant in 5 patients and saw complete recovery in 3 patients $[13,14]$. Since studies have shown repair of the meniscus by using MSC, our objective was to test if chondrocytes injection will heal the meniscus.

\section{Patients and methods}

This is a prospective pilot study to attempt to heal meniscus injuries. An informed written consent was obtained from all the patients who were included in the study. Patients who presented to the Sports Medicine and orthopedic clinics with injury to the knee and a diagnosis of meniscal injury were included. Fifteen consecutive patients were included. The inclusion criteria were patients of either sex, pain in the affected knee and on medication for $\geq 4$ weeks, who were waiting for meniscal repair for more than 3 months. Before including in the study, the evidence of meniscus injury was assessed by diagnostic arthroscopy/Magnetic Resonance imaging (MRI) and VAS of $\geq 5$ (1-10). The exclusion criteria were patients with rheumatoid arthritic knees, septic knees or refusal for consent. The outcome endpoints considered was improvement in the range of movement, improvement in the visual analog scale (VAS), range of movements and MRI.

*Correspondence to: Mir Sadat-Ali, POBOX 40071, King Fahd Hospital of the University Al Khobar 31952, Saudi Arabia, Tel: 966505848281, Fax: 966138820887, E-mail: drsadat@hotmail.com

Key words: meniscus injury, chondrocytes, bone marrow

Received: September 03, 2018; Accepted: September 21, 2018; Published: September 26, 2018 
Under local anesthesia and sedation approximately, $20 \mathrm{cc}$ of bone marrow was aspirated from the patients' anterior superior iliac crest under aseptic standard conditions. The cell aspirant was transported in an equal volume of sterile Bone Marrow Transportation Medium (Hanks Balanced Salt Solution with 10,000 units/mL of penicillin, $10,000 \mu \mathrm{g} / \mathrm{mL}$ of streptomycin and $25 \mu \mathrm{g} / \mathrm{mL}$ amphotericin B. The samples were properly labeled and were immediately transported to laboratory in ice-cold conditions.

\section{Mesenchymal Stimulating Cells (MSC) separation and expansion}

Bone marrow in transportation medium was overlaid on approximately $20 \mathrm{ml}$ of sterile Ficoll-Paque Plus (Merck KGaA, Darmstadt, Germany) taken in a conical centrifuge tube (Sarstedt AG \& Co, Nümbrecht, Germany) and centrifuged in a swing bucket centrifuge (Sorvall ST8, Thermo Fisher Scientific, Massachusetts, USA) at 2000 rpm for 5 minutes at $4^{\circ} \mathrm{C}$. The resultant layer containing mononuclear cells were siphoned out, seeded onto a T75 tissue culture flask (Greiner Bio-One $\mathrm{GmbH}$, Frickenhausen, Germany) at the rate of 5000 cells/ $\mathrm{cm}^{2}$. Approximately $20 \mathrm{ml}$ of MSC culture medium $\left(\mathrm{CTS}^{\mathrm{mm}}\right.$ StemPro $^{\mathrm{mm}}$ MSC SFM, Thermo Fisher, Massachusetts, USA) was added and flask was incubated at $37^{\circ} \mathrm{C}, 5 \% \mathrm{CO}_{2}$ and $95 \% \mathrm{RH}$ in a $\mathrm{CO}_{2}$ incubator. Nonadherent cells were washed off and culture was continued with medium change every two days till cells became confluent. Then the cells were trypsinised, harvested and used for Chondrocyte differentiation. A portion of the cells was used for cell characterization using MSC specific antibodies in flow cytometer (Human MSC Phenotyping Kit from Miltenyl Biotec (Auburn, CA, USA). Expression of CD73, CD90, and CD105 and negative for CD45 was confirmed.

\section{Chondrocyte differentiation}

The MSCs were seeded as high-density cell aggregate micro mass culture using MSC culture medium as mentioned above on a $90 \mathrm{~mm}$ cell culture dish (Nunc, Denmark). After two hours of seeding the medium was washed off and fresh Chondrocyte differentiation medium (CTS Stem Pro MSC medium supplemented with $10^{-7} \mathrm{M}$ dexamethasone, $1 \mu \mathrm{M}$ ascorbate-2-phosphate, $1 \%$ sodium pyruvate and $10 \mathrm{ng} / \mathrm{ml}$ transforming growth factor-beta 1 (TGF- $\beta 1$, Thermo Fisher, Massachusetts, USA). The micro mass culture was further allowed to differentiate for 21 days with medium changes for every 3 days. The cells were harvested at the end of the culture and were characterized for the expression of MMP13 using flow cytometer.

\section{Chondrocyte infusion}

Differentiated and characterized chondrocytes cell suspension was prepared in $0.5 \mathrm{cc}$ of sterile NSS at the rate of $1 \times 10^{6}$ cells/body weight of the patient. The cell suspension was infused intra articular in the knee as a single dose injection in the clinics. Patients were followed up in the clinics and data collected of pain and range of movements. At 3 months range of movements of knee were assessed using Jamar long-arm goniometer and a second MRI was performed. Magnetic Resonance Imaging was used as a preoperative screening measure. MRI was performed on a 3.0 Tesla Siemens Magnetom Skyra machine \#45 384 (Siemens Erlangen, Germany, and acquired in the PAC Scans (picture archiving and communication system) Siemens Healthcare $\mathrm{GmbH}$, Erlangen Germany, proton density, fat saturation was acquired in the coronal and sagittal plane. The view, matrix, and slice thickness were constant in the pre and post injection films. Two independent, university-based musculoskeletal radiologists, who were blinded for the images, reviewed the MRI.

\section{Statistical analysis}

The pre and post injection data was analyzed using students' ' $t$ ' tests for Continuous data were described with the use of descriptive statistics: $\mathrm{n}$, mean, standard deviation, means of the symptoms, probability values $<0.05$ were considered significant. All analyses were conducted with the use of SPSS Inc version 19.

\section{Results}

Sixteen patients with the average age of $34.8 \pm 5.1$ years (range 2342). There were 14 males and 2 females. Two patients were excluded because on arthroscopic examination the meniscus was found to be degenerated with osteoarthritis changes and the rest were traumatic during sporting activities. Table 1 give the other demographic data. As per the classification of the International Knee Documentation Committee (IKDC), 7 meniscal tears were complete and 6 were partial. In Zone 1 there were 5 injuries, 5 were located in zone 2 and 4 in zone 3. There was no bucket handle tear meniscus. In 4 patients the meniscus injury occurred post anterior cruciate ligament reconstruction. There was significant overall improvement in VAS for pain, range of movement and overall satisfaction in 120 days post injection of chondrocytes. The pre-injection pain score was $6.3 \pm 1.25$ and post injection of chondrocytes it was 1.40 .51 ( $\mathrm{p}<0.0001)$. MRI of pre and post chondrocyte injection in the knee joints (Figures 1-3) patients.

\section{Discussion}

Our study shows that with a single intra-articular injection of $10^{5}$ chondrocytes healed the entire injured meniscus in three months'

Table 1. The demographic data

\begin{tabular}{|l|c|}
\hline Age in Years & $34.8 \pm 5.1$ \\
\hline Average Pain Score (Pre-Injection) & $6.3 \pm 1.25$ \\
\hline Average Pain Score (Post Injection) & $1.4 \pm 0.51$ \\
\hline Mean Range of Movement (Flexion) (Pre-Injection) & $90.4 \pm 10.13$ \\
\hline Mean Range of Movement (Flexion) (Post-Injection) & $119 \pm 5.16$ \\
\hline
\end{tabular}

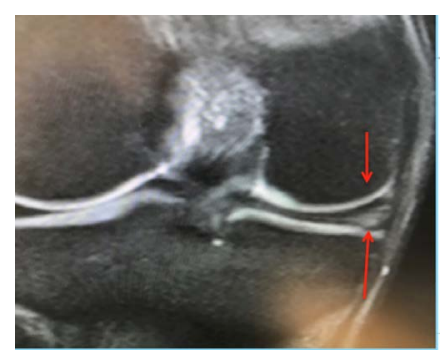

1A

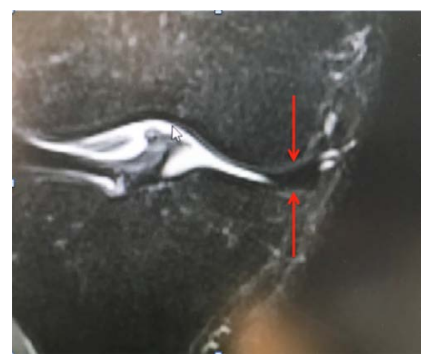

$1 \mathrm{C}$

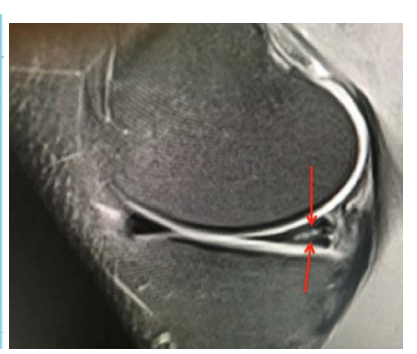

$1 B$

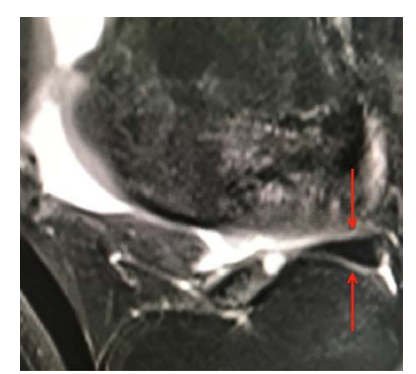

$1 D$
Figure 1. (A, B, C and D) A gradient-echo T2-weighted coronal image demonstrates tear of the body and posterior horn of the medial meniscus, extending to the inferior articular surface, with horizontal orientation of the cleavage. Three months post injection of chondrocytes demonstrate complete resolution of the signal intensity and meniscal shape 


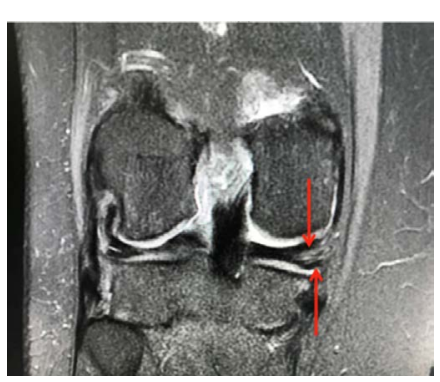

$2 \mathrm{~A}$

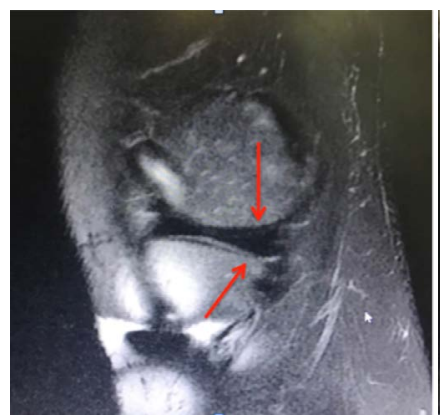

$2 \mathrm{C}$

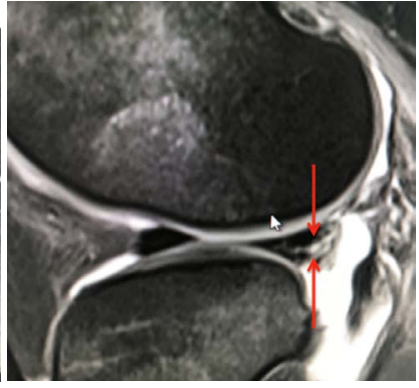

$2 \mathrm{~B}$

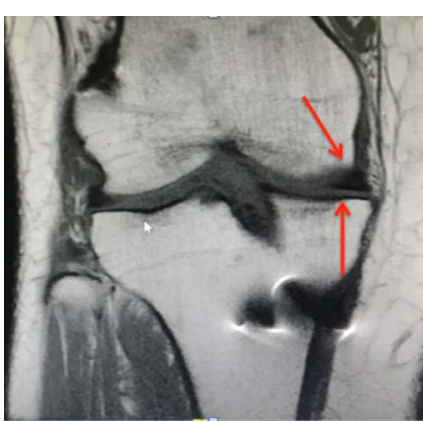

$2 \mathrm{D}$
Figure 2. 42-year-old, MRI of Right Knee, Coronal section medial meniscus shows intrameniscal increased signal intensity suggesting tear reaching the most medial outer surface and inferior articular with associate joint effusion. 42-year-old, post ACL reconstruction, MRI of Right Knee, Coronal section and sagittal views showing healed Medial meniscus

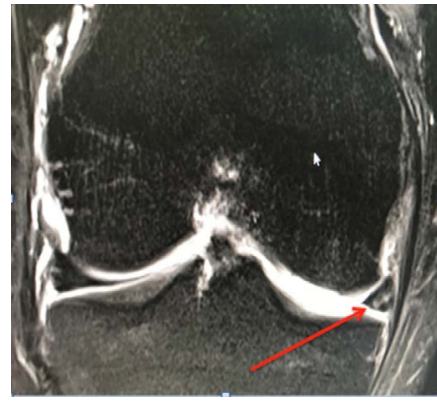

$3 \mathrm{~A}$

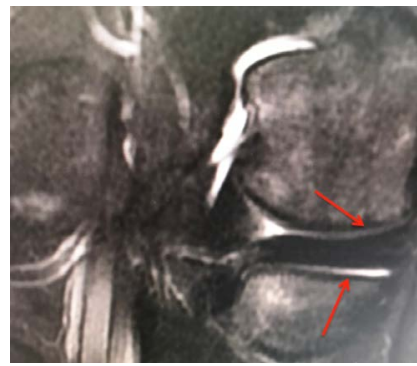

$3 \mathrm{C}$

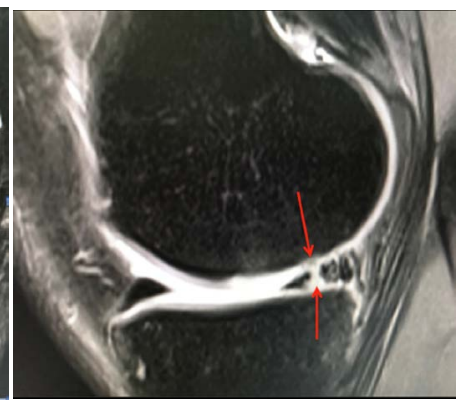

$3 \mathrm{~B}$

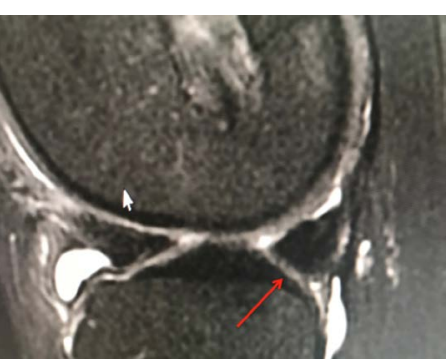

$3 \mathrm{D}$
Figure 3. 40-year-old patients with ACL reconstruction, right knee, coronal and sagittal sections showing in posterior horn medial meniscus complex tear with radial component with extension to both articular surfaces. Post injection of chondrocytes, Figure $3 \mathrm{C}$ and D demonstrate total healing of the meniscus with no signals showing any rent in the meniscus

time based on the MRI and clinical symptoms improved from 4 weeks onwards. Previous attempts to heal injured meniscus was performed with intra-articular injection of stromal vascular fraction (SVF) from adipose tissue-derived stem cells (ASCs) added with platelet-rich plasma (PRP) and showed increased meniscal fibrocartilage volume [15].
Since the meniscus has low healing potential in the avascular zone and questionable to moderate healing rate of the meniscus after the repair in the vascular zone and complications of the repair by various techniques, made clinicians and researchers to find ways for true regeneration of the menisci which will be biomechanically and functional meniscus tissue similar to the natural one [16-18]. Earlier attempts to regenerate the meniscus was attempted by adding blood and fibrin clots, synovial flaps and reparative cells to meniscus tears [19]. Platelet-rich plasma (PRP), which contains the majority of growth factors in the peripheral blood, seems to promote the clinical healing of meniscus tears even in the white-white zone [20,21].

The use of stem cell in the meniscus injuries and post partial meniscectomy got a boost with the results of a randomized, doubleblind, controlled study, in which a single intra articular injection of human mesenchymal stem cells were injected [22]. In a recent review of 543 intra articular knee injections of MSCs due to osteoarthritis with a mean follow up of 24.4 months showed improvement from baseline in at least 1 clinical outcome measure, with no adverse effects [23]. We used differentiated MSCs in the form of chondrocytes with a single injection of 5 million cells and in three months showed significant changes of healing on MRI. In our society young people get meniscus injuries more often and goes through a protracted treatment protocol. The results of our study even though small have implications, which will help the healing of meniscus non-surgically.

Our study has definite limitations. One being a small patient number without a control group, secondly, we relied only on the clinical improvement and quantitative MRI analysis. Another limitation was different severity of the meniscus injury with different meniscus were part of the study. Even with said limitations the strength of the study was the ability to observe the clinical improvement and robust changes of the meniscus tear to normal appearance of the injured meniscus. This study shows that the meniscus can heal under the influence of differentiated MSCs in the form of chondrocytes and has encouraged us to conduct a randomized placebo control study.

\section{Conflicts of interest}

The authors have no conflicts of interest and all authors agreed to submit the manuscript in the present form.

\section{References}

1. McDermott I, Amis A (2006) The consequences of meniscectomy. J Bone Joint Surg $\operatorname{Br}$ 88: 1549-1556. [Crossref]

2. Baker P, Coggon D, Reading I, Barrett D, McLaren M, et al. (2002) Sports injury, occupational physical activity, joint laxity, and meniscal damage. J Rheumatol 29: 557 563. [Crossref]

3. Persson F, Turkiewicz A, Bergkvist D, Neuman P, Englund M (2017) The risk of symptomatic knee osteoarthritis after arthroscopic meniscus repair vs partial meniscectomy vs the general population. Osteoarthritis Cartilage 14: S1063-4584. [Crossref]

4. Petty CA, Lubowitz JH (2012) Does arthroscopic partial meniscectomy always cause arthritis? Sports Med Arthrosc. 20: 58-61 [Crossref]

5. Roos H, Laurén M, Adalberth T, Roos EM, Jonsson K, et al. (1998) Knee osteoarthritis after meniscectomy: prevalence of radiographic changes after twenty-one years, compared with matched controls. Arthritis Rheum 41: 687-693. [Crossref]

6. Bogunovic L, Kruse LM, Haas AK, Huston LJ, Wright RW (2014) outcome of allinside second-generation meniscal repair: minimum five-year follow-up. $J$ Bone Joint Surg Am 96: 1303-1307. [Crossref]

7. Gliatis J, Kouzelis A, Panagopoulos A, Lambiris E (2005) Chondral injury due to migration of a Mitek RapidLoc meniscal repair implant after successful meniscal repair: a case report. Knee Surg Sports Traumatol Arthrosc 13: 280-282. [Crossref] 
8. Grant JA, Wilde J, Miller BS, Bedi A (2012) Comparison of inside-out and all-inside techniques for the repair of isolated meniscal tears: a systematic review. Am J Sports Med 40:459-468. [Crossref]

9. Nepple JJ, Dunn WR, Wright RW (2012) Meniscal repair outcomes at greater than five years: a systematic literature review and meta-analysis. J Bone Joint Surg Am 94: 2222-2227. [Crossref]

10. Yoo JH, Yoon JR, Lee SJ (2008) Parameniscal cyst formation after arthroscopic meniscal repair with biodegradable meniscal arrow: a case report. Knee Surg Sports Traumatol Arthrosc 16: 815-817. [Crossref]

11. Lento PH, Akuthota V (2000) Meniscal injuries: A critical review. J Back Musculoskelet Rehabil 15: 55-62. [Crossref]

12. McDermott ID, Amis AA (2006) The consequences of meniscectomy. J Bone Joint Surg Br 88: 1549-1556. [Crossref]

13. Centeno CJ, Busse D, Kisiday J, Keohan C, Freeman M, Karli D (2008) Increased knee cartilage volume in degenerative joint disease using percutaneously implanted, autologous mesenchymal stem cells. Pain Physician 11: 343-53. [Crossref]

14. Whitehouse MR, Howells NR, Parry MC, Austin E, Kafienah W, et al. (2017) Repair of torn avascular meniscal cartilage using undifferentiated autologous mesenchymal stem cells: from in vitro optimization to a first-in-human study. Stem Cells Transl Med 6: 1237-1248. [Crossref]

15. Park J, Lee JH, Park KS, Park M, Kang LW, et al. (2017) Current use of autologous adipose tissue- derived stromal vascular fraction cells for orthopedic applications. $J$ Biomed Sci 24:9. [Crossref]
16. Austin KS, Sherman OH (1993) Complications of arthroscopic meniscal repair. Am J Sports Med 21: 864-868. [Crossref]

17. Bach BR Jr, Dennis M, Balin J, Hayden J (2005) Arthroscopic meniscal repair: analysis of treatment failures. J Knee Surg 18: 278-284. [Crossref]

18. Hasan J, Fisher J, Ingham E (2014) Current strategies in meniscal regeneration. $J$ Biomed Mater Res B Appl Biomater 102: 619-634. [Crossref]

19. Scotti C, Hirschmann MT, Antinolfi P, Martin I, Peretti GM (2013) Meniscus repair and regeneration: review on current methods and research potential. Eur Cell Mater 26:150-170. [Crossref]

20. Stärke C, Kopf S, Petersen W, Becker R (2009) Meniscal repair. Arthroscopy 25: 1033 1044. [Crossref]

21. Wei LC, Gao SG, Xu M, Jiang W, Tian J, et al. (2012) A novel hypothesis: the application of platelet-rich plasma can promote the clinical healing of white-white meniscal tears. Med Sci Monit 18: HY47-50. [Crossref]

22. Vangsness CT, Farr J, Boyd J, Dellaero DT, Mills CR, et al. (2014) Adult human mesenchymal stem cells delivered via intra-articular injection to the knee following partial medial meniscectomy: a randomized, double-blind, controlled study. $J$ Bone Joint Surg Am 96: 90-98. [Crossref]

23. McIntyre JA, Jones IA, Han B, Vangsness CT (2017) Intra-articular mesenchyma stem cell therapy for the human joint: A Systematic Review. Am J Sports Med 884 [Crossref]

Copyright: (C2018 AlSayed HN. This is an open-access article distributed under the terms of the Creative Commons Attribution License, which permits unrestricted use, distribution, and reproduction in any medium, provided the original author and source are credited. 